\title{
Orthopaedic sports surgery: art or science?
}

\author{
J. Espregueira-Mendes · M. Karahan
}

Published online: 11 March 2014

(c) Springer-Verlag Berlin Heidelberg 2014

Have you ever known any young resident full of ambition and knowledge but unable to perform a basic bone drilling despite numerous attempts? On the opposite, did you ever meet a young resident, strikingly skillful however missing basic theoretical concepts? It is statistically inevitable that you will encounter both if you have been training young colleagues for an amount of time. It is responsibility of a teaching mentor to identify the qualities and pitfalls of each trainee, from an educational perspective, so you can get the best out of both characters.

Despite our profession is also considered an "art", there are three fundamental columns that will define the "science" within a successful surgeon. First, any surgeon should know the anatomy, physiopathology, the diagnostic algorithm and state of the art of treatment methods. The same surgeon should have the motivation to interact, listen and understand the physical and emotional requirements of the human being who came to ask him for help—create empathy. Last but not least, the surgeon should have musculoskeletal ability to perform the planned course of action. From arthroscopic minimally invasive to trauma or arthroplasty revision procedures, basic motor skills must be earned, trained and performed safely and confidently.

A motor skill is a function, which involves the precise movement of muscles with the intent to perform a specific

\footnotetext{
J. Espregueira-Mendes ( $₫)$

Orthopaedic Department, 3B'S, ICVS, Minho University, Porto, Portugal

e-mail: jem@espregueira.com

J. Espregueira-Mendes

Dragão Stadium, FIFA Medical Centre of Excellence,

Clínica Espregueira-Mendes, Porto, Portugal

M. Karahan

Acibadem University, Istanbul, Turkey
}

act [1]. A motor skill could be defined as discrete acts, such as introducing needle into a joint, or continuous such as arthroscopic partial meniscectomy. Classical way of motor skill teaching based on Halsted's principles (hands on) is stalled due to various reasons lead by medical-legal issues [2]. However, residents have to be trained effectively until they are expected to operate on patients.

A child is not expected to pay a full court game when he starts to learn basketball. He is first taught how to hold, pass and dribble the ball. Development of further fundamental acts of the game will follow. Teaching the residents basic motor skill acts before expecting them to perform a "full court game" seems more suitable [3].

Concerning surgery, the training should be adapted to individual needs, individualized but under a supervised education programme.

Joint models, basic motor skill instruments, animal cadavers, simulators and human cadavers fortunately provide the residents suitable ways for learning motor skills [4]. Among these, some are inexpensive and low-fidelity, whereas some are expensive and high fidelity. Moreover, not all institutions will be able to afford every of the referred options. However, you have the responsibility to get the most of what you have. If these measures are presented within an educational philosophy, they will be able to make some change in the motor skill performance of the learner [5].

They need to know that the latest technique is not always the greatest, despite we should not destroy their enthusiasm to develop new options. We must recognize that residents have different skills but, in the end, they all must acquire some basic knowledge and skills. We should not destroy the "art" some of them carry inside; instead we should help them tune it to become effective. We must enhance some brilliant scientific minds in order to make them practical to bring it to operative purposes. 
They will have different capacities, but all of them must be competent and trustable surgeons. This is also our responsibility as educational responsible.

Today the young residents will thank us. Tomorrow we will also be among their patients...

\section{References}

1. Willingham DB (1998) A neuropsychological theory of motor skill learning. Psychol Rev 105:558-584
2. Carter BN (1952) The fruition of Halsted's concept of surgical training. Surgery $32: 518$

3. Neiman Z (1989) Teaching specific motor skills for conducting to young music students. Percept Mot Skills 68:847-858

4. Bell RH Jr (2004) Alternative training models for surgical residency. Surg Clin N Am 84:1699-1711

5. Dubrowski AI, Backstein D (2004) The contributions of kinesiology to surgical education. J Bone Joint Surg Am 86(12):2778-2781 